Review

\title{
Conceptualising Multilingual Capabilities in Anglophone Higher Degree Research Education: Challenges and Possibilities for Reconfiguring Language Practices and Policies
}

Wei Liu

Centre for Educational Research, School of Education, Western Sydney University, Penrith, NSW 2751, Australia; W.Liu@westernsydney.edu.au; Tel.: +61-468-879-849

Academic Editor: James Albright

Received: 27 September 2016; Accepted: 16 November 2016; Published: 24 November 2016

\begin{abstract}
In a context of the internationalisation of Higher Education (HE) driven by the high mobility of international Higher Degree Research candidates (HDRs), it is important to consider the value of HDRs' multilingual capabilities for their learning and making of original contributions to knowledge. This article reports on a literature study regarding conceptualisations of multilingualism and multilingual capabilities, together with multilingualism in university research education practices and policies. Key themes to emerge from the literature include divergent understandings of languages, multilingualism, and multilingual capabilities. For example, a 'static' language construct provides a structuralist lens through which multilingual HDRs are viewed as an accumulation of monolinguals, whereas a 'dynamic' language construct informs a socially and culturally constructed linguistic space where the multilingual resources of HDRs are valued. These divergences are manifested in the language-as-problem orientation and language-as-resource orientation in anglophone universities' HDR education policies. Informed by empirical evidence of leveraging multilingual capabilities in original contributions to knowledge, this article argues that it is urgent for pertinent stakeholders in HDR education to reconfigure language practices and policies in the HDR educational context. In doing so, the voices of HDRs would be able to leverage multilingual capabilities in their research instead of being treated as deficient English learners.
\end{abstract}

Keywords: multilingualism; multilingual capabilities; language policies; multilingual practices; Higher Degree Research education; multilingual Higher Degree Research candidates; anglophone universities

\section{Introduction}

A "high standard of English and a professional standard of presentation" are stipulated criteria in the Higher Degree Research Examination Handbook 2016 issued by the Graduate Research School, Western Sydney University [1]. These criteria apply uniformly to all Higher Degree Research candidates (HDRs), whether monolingual anglophones or multilingual. Australian anglophone universities use an English-only medium instruction, which has been reinforced by the desire of international multilingual HDRs to improve their English in today's English-dominant globalised world [2]. However, this article problematizes the familiar, taken-for-granted monolingual norms of Higher Degree Research (HDR) education in anglophone universities. It is debatable whether this exclusionary English-only agenda is preferable for educating multilingual HDRs, given that their multilingual capabilities and associated knowledge have been marginalised.

Multilingualism has been widely discussed in relation to the internationalisation of Higher Education (HE) driven by globalisation [3-7]. According to Australian Education International [8], $31.5 \%$ of all HDRs enrolled at Australian Higher Education Institutions (HEIs) were international 
students in 2014, the majority of whom had multilingual capabilities. Accordingly, educating these multilingual HDRs presents challenges to HEIs in Australia. However, Mitchell's analysis of education policies found that multilingual students are characterised as "either academic failures [with an] English deficiency or invisible in policies and practice" [9] (p. 13). Research indicates that English-only monolingualism raises educational and ethical issues concerning students' struggles to maintain their multilingual capabilities at acceptable levels of proficiency in academic domains $[6,10]$. Using epigraphs composed in their original languages at the beginning of each chapter, Gordin [11] reminds us that the production of scientific knowledge has always been, and continues to be, undertaken in multiple languages. Concerns about the negative consequences for research, and English-only monolingualistic research education of multilingual HDRs have led to investigations of ways to capitalise on their multiple languages in their research. For example, Singh et al. argue that although anglophone universities make ethno-cultural differences a point of interest, they still position linguistic diversities as "a deficit or threat" [12] (p. 55). Therefore, this article investigates the contestations informing concepts of multilingualism and multilingual capabilities in education [13]. Together with research into the tensions between universities' monolingual education policies and HDRs' multilingual practices, a phenomenon dubbed 'the postmonolingual condition' by Yildiz [14], this paper explores the challenges and possibilities for creating an intellectual space for multilingual HDR education.

\section{Complexities of Conceptualising Multilingualism}

Multilingualism is a complicated construct. Its definition is embedded in diverse theoretical and practical angles which emphasise "different aspects of using and learning languages" [15] (p. 1). A basic entry point to understanding this concept might usefully rest upon an appreciation of the competing interpretations of the meaning and uses of multiple languages by HEIs at anglophone universities. This section begins by examining how languages are regarded differently in various multilingual contexts. This is followed by investigating the problems with the naming of bilingualism and plurilingualism.

\subsection{Conceptualising Languages}

Two contrasting views towards languages have been addressed in the context of multilingualism. The concept 'language' is here understood as "a variety that a group adopts as a habitual way for communication" [13] (p. 344). According to Koven, there are "folk beliefs that see [any] language as external to and merely describing a fully constituted core self that is stable across contexts" [16] (p. 4). In response to this view, Cruz-Ferreira [17] (p. 1) states that "multilingualism has nothing to do with particular languages, because languages cannot be multilingual". Assumptions that regard languages as "objects amenable to both inspection and possession by human beings" lead to conceptualising multilingualism as simply an "accumulation of languages [by monolinguals]" [17] (pp. 3-5). This does not account for the many loan words from diverse languages that now constitute English and Chinese.

Instead of viewing languages as "objects", others focus on the social uses of languages as a "continuously monitored creative activity" [18] (n.p.). This contention has been corroborated by García and Wei's [19] (p. 7 and p. 201) use of "languaging", which suggests conceptualising languages as "a series of social practices and actions" in investigations of multilingualism. Separating languages from their users and contexts is not capable of informing "how languages are put to work" [17] (p. 5).

More recent studies of multilingualism offer "complex and fluid understandings about languages" [20] (p. 421). Taking "translanguaging" as an example, García and Leiva [21] (p. 200) use this term to refer to "the flexible use of linguistic resources by bilinguals [or multilinguals] in order to make sense of their world". In this sense, languages are viewed as "entire linguistic repertoires" activated in multilinguals' daily-lived language practices [20] (p. 421). Accordingly, this view favours exploring how multilingual HDRs might better leverage their entire linguistic repertoires to make sense of academic learning and make original contributions to knowledge in their research. 


\subsection{Problems with Naming Bilingualism}

The interchangeability of bilingualism and multilingualism has been called into question. There is a lack of consensus about whether "bilingualism and multilingualism constitute ... the same phenomenon" [15] (p. 4). It is argued that multilinguals have "larger overall linguistic repertoires ... and a wider range of language situations" [15] (p. 5). Particularly, bilinguals and multilinguals differ as to learning experiences and strategies in specific education areas, such as Second Language Acquisition [22,23]. Some scholars treat multilingualism as "a kind of multiple bilingualism" [24] (p. 9). For example, Beardsmore [25] (p. 3) defines bilingualism in a way "[that] does not necessarily restrict itself to situations where only two languages are involved but is often used as a shorthand form to embrace cases of multi- or plurilingualism". In this sense, bilingualism and multilingualism are interchangeable notions in some academic discussions. Wei's [26] (p. 7) definition of bilingual illustrates this proposition:

'bilingual' primarily describes someone with possession of two languages. It can, however, also be taken to include the many people in the world who have varying degrees of proficiency in and interchangeably use three, four or even more languages.

Given the debate over the relationship between bilingualism and multilingualism, an additional concept, plurilingualism, needs to be considered.

\subsection{Problems with Naming Plurilingualism}

A terminological shift from multilingualism to plurilingualism has emerged recently in educational research in Europe. The term plurilingualism is used to highlight individual students' linguistic repertoires and dispositions [27,28]. In contrast, according to the Council of Europe [29] (p. 4), multilingualism is understood as "the knowledge of a number of languages or the co-existence of different languages in a given society". Cenoz [22] argues that this distinction is the same as the one between individual and societal multilingualism. Therefore, the use of plurilingualism seems to be problematic in its apparent exclusion of considerations of societal multilingualism. Both individual and societal multilingualism are educationally important [30].

Given the forgoing, multilingualism is the concept used in this article to include concepts of bilingualism and plurilingualism. In this regard, studies of HDRs' multilingual education are not restricted to linguistic practices in just two languages or to individuals' language use.

\subsection{Debating Definitions of Multilingualism}

Defining multilingualism is as complex as it is contentious. In part, this is because multilingualism is studied from different perspectives across various disciplines such as psycholinguistics, sociolinguistics, language education, and language planning policy [22]. Table 1 indicates dimensions relevant to defining multilingualism, namely proficiency levels, individual and societal dimensions, and subtractive and additive elements.

Different dimensions used for defining multilingualism are presented in Table 1 . This is not an exhaustive list. For example, receptive and productive multilingualism are not mentioned here because the multilingual HDRs discussed in this paper are capable of understanding and producing spoken or written languages [30]. It is important to remember that each dimension is problematic.

First, a restrictive view towards multilingualism leads university educators, administrators, policy makers, and researchers to regard multilingual HDRs as having two or more monolingual capabilities in one person [35]. On the other hand, Edwards' [33] 'c'est la vie' liberal view contests the appropriateness of this. Therefore, valuing HDRs' multilingual capabilities calls for a departure from a focus on the amount and diversity of language experience and uses in HDRs' education and research [36]. In this regard, university educators and policy-makers may raise awareness of the value of HDRs' multilingual capabilities. Thus, multilingual HDRs are enabled to "maximise" their original contributions to knowledge through "draw[ing] from across all their existing language skills" [37] (p. 607). 
Table 1. Dimensions relevant to defining multilingualism.

\begin{tabular}{|c|c|c|}
\hline Dimension & \multicolumn{2}{|c|}{ Defining Multilingualism } \\
\hline \multirow{4}{*}{ Proficiency } & Restrictive View & Liberal View \\
\hline & $\begin{array}{l}\text { Multilingualism is defined as "native-like } \\
\text { control of two or more languages" [31] (p. 56) } \\
\text { or "active, completely equal mastery of two } \\
\text { or more languages" from a restrictive } \\
\text { perspective [15] (p. 2). }\end{array}$ & $\begin{array}{l}\text { Those who have "at least some knowledge and } \\
\text { control of the grammatical structure of the } \\
\text { second [third] language" are multilinguals [32] } \\
\text { (p. 14). For example, "[i]f, as an English speaker, } \\
\text { you can say c'est la vie or gracias or guten tag or } \\
\text { tovarisch-or even if you understand them", } \\
\text { you are a multilingual [33] (p. 55). }\end{array}$ \\
\hline & \multicolumn{2}{|c|}{ Problem } \\
\hline & $\begin{array}{l}\text { The restrictive view raises questions about } \\
\text { defining proficiency level, use frequency, and } \\
\text { flexibility [30]. }\end{array}$ & $\begin{array}{l}\text { In the liberal view, most of the population in } \\
\text { many countries such as Australia can be } \\
\text { regarded as multilinguals due to global flow } \\
\text { of people [30]. }\end{array}$ \\
\hline \multirow{4}{*}{ Individual \& Societal } & Individual & Societal \\
\hline & $\begin{array}{l}\text { Individual language competences and } \\
\text { abilities are in the foreground, such as } \\
\text { plurilingualism, bi-multi-linguality [15]. }\end{array}$ & $\begin{array}{l}\text { A multilingual society is defined as Belgian, } \\
\text { due to the "existence of consistent historical } \\
\text { language groups" [34] (p. 346). }\end{array}$ \\
\hline & \multicolumn{2}{|c|}{ Problem } \\
\hline & \multicolumn{2}{|c|}{ Individual and societal multilingualism are not separate, but manifest different emphases $[22,30]$. } \\
\hline \multirow{4}{*}{ Additive \& Subtractive } & Additive & Subtractive \\
\hline & $\begin{array}{l}\text { Learning a new language represents the } \\
\text { expansion of students' intellectual repertoire. } \\
\text { For example, 'elite' multilingualism driven by } \\
\text { a thirst for knowledge and cultural boundary, } \\
\text { such as the prestigious languages Greek and } \\
\text { Latin in ancient times [30]. }\end{array}$ & $\begin{array}{l}\text { One language, usually English in Australia and } \\
\text { Putonghua in China, is more ascendant and the } \\
\text { others are waning. } \\
\text { For example, 'folk' multilingualism driven by } \\
\text { informal and daily-life necessity, such as } \\
\text { immigrant school children [30]. }\end{array}$ \\
\hline & \multicolumn{2}{|c|}{ Problem } \\
\hline & $\begin{array}{l}\text { This distinction between additive multilingual } \\
\text { depends upon whether, and indicates whether } \\
\text { weak/minoritised in the specific social context }\end{array}$ & $\begin{array}{l}\text { ism and subtractive multilingualism highly } \\
\text { the languages are strong/prestigious or }\end{array}$ \\
\hline
\end{tabular}

Second, discussions of individual multilingualism emphasise the linguistic and psycholinguistic dimension, whereas sociolinguistic dimensions focus on the historical, educational, and political considerations at the university and larger societal level. All languages and the knowledge they provide access to are "socially contingent and dynamic" [36] (p. 229). Societal multilingualism is contested as it needs to be "officially endorsed", for instance by universities [30] (p. 6). The problem is to distinguish between official and de facto multilingualism and monolingualism. Australia, for example, is a multilingual society where English is the "de facto official language" existing in tension and support with other languages [38] (p. 163). Are Australian universities monolingual or multilingual? The same question applies to China as well. Putonghua (Mandarin) has been stipulated as the official language of China since 1949, yet there are 56 distinct ethnic groups speaking more than 400 other languages [39].

Third, the additive and subtractive dimensions are mainly addressed in Second Language Acquisition from a psycholinguistic perspective. However, in advocating a holistic approach to multilingual education, Cenoz and Gorter [40] (p. 5) suggest a continuum between "becoming multilingual" and "being multilingual". This continuum echoes with waning dichotomies between psycholinguistic and sociolinguistic studies on multilingualism [19]. As Franceschini [13] (p. 352) states, "multilingualism is complex in its foundation (social and cognitive) ... A separation into clear-cut disciplines in analysing multilingual phenomena seems obsolete". Therefore, under a post-structuralist approach, HDRs' multilingual practices may be regarded as "a process of using languages to gain knowledge, to make sense, to articulate one's thought" [41] (p. 1224). According to García and Wei [19] (p. 7), a post-structuralist construct sees languages as tools that "are re-appropriated by actual users" 
and "speakers are embedded in a web of social and cognitive relations". In other words, HDRs can use their full linguistic repertoires to gain knowledge, to make sense of or theorise evidence, and to articulate analytical concepts.

Who can be treated as "multilinguals" and what might count as "multilingualism" may not yield a final argument. Franceschini [13] (p. 352) suggests that "an inclusion of different views is necessary" as multilingualism "concerns the development of knowledge and is observable in social interaction and discourse". The concern for HDRs' multilingual capabilities lies in the potential for developing original contributions to knowledge. This echoes Liddicoat's [42] (p. 10) statement that "multilingualism can be both an object of study and a form of engagement with knowledge". Given the forgoing, Franceschini [34] (p. 33) defines multilingualism as "the capacity of societies, institutions, groups, and [multilingual HDR] individuals to engage on a regular basis in space and time with more than one language in everyday [academic] life".

\section{Conceptualising Multilingual Capabilities}

This section begins by examining how languages are regarded differently in various multilingual contexts. This is followed by investigating the problems with the naming of bilingualism and plurilingualism. Conceptualising multilingual capabilities enables relevant agents to raise awareness of the benefits of allowing HDRs' voices in multiple languages to be used in their academic learning $[7,12]$. The idea of multilingual competence is rooted in Chomsky's [43] concept of linguistic competence. Chomsky's (2009) concept of linguistic competence is a structuralist theoretical construct about human beings' potential for acquiring, producing, and understanding language. It is about the knowledge attributed to an ideal speaker-hearer in a homogeneous speech community. However, a capability approach is used here to regard multilingual HDRs' human life as a set of "doings and beings", dubbed as "functionings" [44] (p. 320). Here, a functioning is an achievement of a multilingual HDR candidate "what he or she manages to do or to be, and any such functioning reflects" [44] (p. 321). Here, the concepts of multicompetence, code-meshing and translanguaging are scrutinised [19,45,46].

Based on Chomsky's [43] notion of linguistic competence, the concept of multicompetence was first formulated by Cook [45] (p. 112) as "the compound state of a mind with two grammars". However, it was subsequently questioned due to a lack of "social embeddedness" [13] (p. 350). In response to criticism, this term was broadened to incorporate a sociolinguistic point of view in multilingual education as part of the students' multilingual capabilities that develop throughout their interactions with the educational or social environment [13]. This notion was further reformulated to explain it is "not confined to the language aspects of the mind but is also linked to cognitive processes and concepts" [19] (p. 10).

The term code-meshing was coined to denote that multilingual learners are capable of using full linguistic repertoires in academic writing. According to Michael-Luna and Canagarajah [47] (p. 56), code-meshing is used by multilingual learners intentionally to integrate "local and academic discourse as a form of resistance, reappropriation, and/or transformation of the academic discourse". Translanguaging has been defined as a cognitive multicompetence [19]. However, García and Wei [19] (p. 40) claim that translanguaging is "a meaning-making social and cognitive activity that works in-between conventional meaning-making practices and disciplines". Under the umbrella of translanguaging, multilinguals are enabled to "select meaning-making features and freely combine them to potentialize meaning-making, cognitive engagement, creativity, and criticality" [19] (p. 42).

Subsuming the multilingual capabilities of HDRs within any one of the aforementioned three concepts is contentious. Going beyond these three concepts, it is possible to view languages as "resources of thought" [48] (p. 140). To activate languages as "resources of thought", Jullien [48] suggests using the divergences between languages as resources for thought to invoke multilingual HDRs as equally intelligent agents. In this regard, the multilingual capabilities of HDRs are not restricted within Chomskian grammatical competence or communicative competence [49]. Hymes [49] (p. 282) defined communicative competence from a sociolinguistic perspective as the capabilities of 
a person to use language appropriately in a specific context. Beyond this view, HDRs can be seen as using their multilingual repertoires to perform their 'functioning' as researchers [12]. This means multilingual HDRs mobilise "their own unique repertoire of meaning-making resources" in original knowledge contribution [19] (p. 80).

\section{Conceptualising Multilingualism in Education: Practices and Policies}

To analyse language planning issues in multilingual education in the United States, Ruíz [50] established a language-as-resource (LAR) orientation and a language-as-problem (LAP) orientation. Here, orientation refers to "a complex of dispositions toward language and its role, and toward languages and their role in society" [50] (p. 16). The LAR orientation regards multiple languages as "supportive of learning and teaching" [7] (p. 6). In contrast, multilingual HDRs are constructed as lacking language proficiency within the LAP orientation [50]. Moreover, the LAP orientation reduces learning to language mastery by providing academic literacy support to typically monolingual programs in English for multilingual HDRs [9].

\subsection{Language-as-Resource (LAR) Orientation}

Scholars have addressed students' learning benefits from activation of their multilingual resources [7,12,51-54]. For example, Basque scholars suggest that "the systematic and deliberate use of mother tongue is advocated to avoid a sense of failure, lack of ability, and the loss of identity" [55] (p. 183). In addressing academic literacy, Van der Walt [7] (p. 121) reports that academic multiliteracies see multilingual students as empowered to "consciously use more than one language while they engage with text ... draw on the linguistic resources at their disposal". In order to achieve the successful application of their multilingual capabilities to original contributions to knowledge, educational support from universities is essential, so that multilingual HDRs can fully benefit from such advantages [56]. The aforementioned evidence for LAR orientation is testament to the possible educational benefits of engaging the multilingual capabilities of HDRs [3].

However, the LAR approach to educating multilingual HDRs is not "as unproblematic as it may sound" [7] (p. 7). It is a challenge to many who have a stake in LAP in particular. As Heller and Pavlenko [57] (p. 71) note, multilingual students are subject to scrutiny "because of the challenge they have presented to prevailing ideologies". Currently, LAP has secured a legitimate place in anglophone universities for offering academic or language support. Van der Walt [7] (p. 7) refers to these "interventions" as being imposed on multilingual students who have successfully gained access to anglophone HEIs "based on prior performance in another language". However, these multilingual capabilities and prior knowledge turn out to be invisible in university policy and practices [9]. In this regard, a monolingual focus which constructs these students' multilingualism as a problem becomes particularly questionable [7].

\subsection{Language-as-Problem (LAP) Orientation}

One instantiation of LAP orientation in anglophone universities is the privileging English-only monolingualism, under which students' multilingual capabilities are ignored. According to Yildiz [14] (p. 2), monolingualism designates "the presence of just one language" and "constitutes a key structuring principle [where] individuals and social formations are imaged to possess one 'true' language ... and through this possession to be organically linked to an exclusive, clearly demarcated ethnicity, culture, and nation". A key exclusionary marker is the official labels assigned to multilingual students that always announce deficiencies in their English. For example, Mitchell [9] (p. 1) reports that monolingual education policies in the United States marginalise the capabilities of multilingual students: 
... most states in the United States identify the subgroup of multilingual learners only in terms of their "Limited English Proficiency" (LEP) or as "English Language Learners" (ELL) and otherwise overlook the population in policy and data analyses.

English is portrayed as the language of mobility and access to global academic markets [7]. However, Maingueneau [2] questions whether an English-only scientific world is favourable for the production and circulation of knowledge. This view resonates with Van der Walt's [7] (p. 47) concerns that the lack of recognition for multilingual research is such that "the context and materials available in other languages are not acknowledged". The issue also arises with respect to academic achievement assessment policies. For example, Shohamy [58] (p. 418) argues that the English-only monolingual tests imposed on multilingual students send the "message that multilingual knowledge is a liability".

In universities, multilingual HDRs are trained and assessed using English-only monolingual norms as the standard [4]. Research into Australian higher education policies reports that English-only monolingualism frames the research curriculum and assessment practices for linguistically diverse HDRs $[4,59,60]$. Against this LAP orientation, there is an increasing awareness of the value of languages. Researches are questioning the dissonance between monolingual policies and multilingual practices $[5,14,56]$. HDRs' multilingual capabilities are being activated, mobilised, and developed in research education to facilitate original contributions to knowledge [12].

\section{Leveraging HDRs' Multilingual Capabilities for Original Knowledge Contribution}

One criterion for assessing HDRs' theses is that they make original contributions to knowledge. For instance, the WSU Higher Degree Research Examination Handbook 2016 stipulates: "Your thesis should make an original contribution to the knowledge of the subject in the area of your research" [1] (p. 9, italics added). An original contribution to knowledge appears as a universal criterion for awarding a doctoral thesis [61-63]. It is commonly agreed that a doctoral study enables HDRs to "become innovative as researchers, through developing their ability to create new ideas" [64] (p. 5). Nonetheless, each key word here is contentious. Poole (2015) [62] states that notions of "originality", "contribution", and "new knowledge" are inherently polysemous in investigating what a doctorate is or should be. These assessments also evaluate whether HDR candidates' research "has made a contribution to the intellectual field that changes the way in which that field is understood" as a yard stick [62] (p. 1515).

The core idea of LAR in multilingual education is to add value to the multilingual intellectual strengths of HDRs [65]. Taking this view as a departure point, this section analyses the use of HDRs' multilingual capabilities for enhancing their original contributions to knowledge $[12,66,67]$.

\subsection{Testaments of Multilingual Capabilities in Original Contributions to Knowledge}

English-only pedagogies and Euro-American intellectual colonialism hinder original contributions to knowledge. Against this, engagement with HDRs' multilingual capabilities is supported by some anglophone research educators [12,66-69]. When supervising international and domestic indigenous HDRs, Manathunga [66] (p. 81) employs an "open" epistemological standpoint to "extend their thinking repertoires". To deepen the multilingual capabilities of Chinese HDRs, the educational metaphor yīn cái shī jiào (因材施教) is used for encouraging theorising in post-monolingual anglophone HDR education [70]. Singh's (2011) [69] pedagogies informed Qi's [67] use of the Anglo-Chinese concept of networked-hutong siwei to theorise transnational teacher education.

These studies are testaments to anglophone research educators' leveraging of the multilingual capabilities of HDRs into making original contributions to knowledge to acknowledge, using their full linguistic repertoires. However, the problem here is that these multilingual academic achievements are not explicitly recognised in anglophone universities' current English-only research educational policies. According to Hornberger and Link [71] (p. 261), interacting with educational policy provides opportunities for both educators and HDRs to create "new spaces to be exploited for innovative [multilingual research] programs, curricula, and practices that recognize, value, and build on the multiple, mobile communicative [intellectual] repertoires". 


\subsection{Challenges of Legitimising HDRs' Multilingual Capabilities}

Legitimatising HDRs' multilingual capabilities as valuable resources in university research education policies might enable a new intellectual space for generating innovations. Maingueneau [2] (p. 115) argues that "creativity in social and human sciences benefits from preserving a plurality scientific production spaces than from a single homogeneous space, which usually tends to fall in complacency". By questioning English-only monolingualism for limiting the production and circulation of knowledge, Maingueneau [2] (p. 118) suggests that:

It is not a matter of rejecting English as the dominant language for the worldwide circulation of knowledge, but of combating the idea that widespread monolingualism would favour, by definition, the creation of knowledge.

This argument resonates with Van der Walt's [7] concerns that the education context and resources available in other languages need to be acknowledged by anglophone universities. Without legitimate support from formal university policies, Arya et al. [72] argue that English-only language-based ideologies and stereotypes threaten to affect multilingual HDRs' academic achievement.

The factors contributing to the prevalence of English-only monolingualism in university research education policies can be interpreted from various perspectives. From a nation-state perspective, a single national language is a political device, serving as a symbol and mechanism to promote collective national identities [73]. In this regard, monolingual university research education policies are a product of, and contribute to, the 'one nation, one language' ideology. English-only monolingualism perpetuates and imposes such an ideology. Another factor concerns asymmetries in the sociolinguistic order. In today's world, English is the lingua franca in academic, educational, and research fields, leading to the reproduction of English-only monolingual norms [11]. Not surprisingly, in academic research writing, Michael-Luna and Canagarajah [47] (p. 70) argue that "vernacular discourses are often treated as unsophisticated by the social mainstream and the in-groups of HE writing". Further, beyond linguistic 'racism', an Anglo-centred epistemological world system in which non-Western theorising is considered as inferior. Dubbed as epistemic racism [10], this serves as a catalyst for producing English-only monolingual norms in the university education field, particularly in research education.

\section{Conclusions}

There is evidence that the multilingual capabilities of HDRs can be leveraged in anglophone universities to make an original contribution to knowledge [12,67-70], despite multilingual HDRs being trained and assessed under English-only monolingual university policies [4]. Ignoring the multilingual capabilities of HDRs is a barrier to original knowledge production. Assumptions about linguistic homogeneity and rejection of student languages and intellectual cultures do little to advance much needed innovative ideas [12,56]. That the multilingual capabilities of HDRs might be valued in official HDR education policies warrants close consideration.

The challenges to generating new configurations of language practices and educating multilingual HDRs manifest the struggles with old, dated conceptualisations of languages, multilingualism, and multilingual capabilities. The assumption that languages are separate autonomous entities mystifies the value of multilingual resources $[17,46]$. Languages are better viewed as "a product of the deeply social and cultural activities in which people engage" for meaning-making [74] (p. 1). Structuralism constructs language as an abstract system governed by signs and sign processes, and ignores how multilingual HDRs use their linguistic and cultural knowledge in real-time research work [19]. A post-structuralist approach to languages embraces multilingualism as a socially and cognitively constructed phenomenon. In this sense, multilingual HDRs appropriate their multiple languages throughout their research practices with or without universities' authority. To challenge the old understandings of language which are restricted to grammatical and communicative issues, multilingual HDRs can use their multilingual repertoires to perform diverse research functionings at the theoretical level in their lived academic work $[12,28]$. 
Addressing the dissonance between English-only monolingual university policies and multilingual HDRs' practices requires consideration of more factors at different levels. For example, at the nation-state level, Australian universities operate under the unquestioned assumption that a single language-English—is the norm for assessing HDR theses [56,75]. English-only monolingualism is used exclusively as the dominant medium for research, even though evidence may be collected and analysed in other languages [12]. The English-only monolingual assumption is reinforced through academics' professional preparation and in-service work [76]. Against the reinforcement of English-only monolingualism, the explicit presence of multilingual policies for HDR educators warrants consideration.

The absence of explicit multilingual policies in anglophone universities creates a space where educators and multilingual HDRs can "exercise agency in reinterpreting, challenging, and reforming dominant practice" [56]. Thus, there is a need for research which explores how multilingual HDRs can use their multilingual capabilities in facilitating their learning and in making an original contribution to knowledge in their everyday research. This might shed light on ways to reconfigure language practices and policies in this field. This article reviewed empirical evidence which suggests the prospects for creating a multilingual space where the multilingual capabilities of HDRs can be engaged and recognised for their value in facilitating original contributions to knowledge. As Hornberger [77] (p. 198) states, "there are many unanswered questions and doubts surrounding multilingual education as to policy and implementation". This is particularly true with respect to the reconfiguration of HDR education polices in English-only anglophone HEIs. Change cannot be achieved without the collaboration of stakeholders in the HDR educational field.

Acknowledgments: Liu Wei gratefully acknowledges the research education provided by Michael Singh which has informed her research project. Many thanks are also due to Jing Qi and Dennis Abbott for valuable comments on this article. This work is financially supported by the China Scholarship Council.

Conflicts of Interest: The authors declare no conflict of interest.

\section{References}

1. Western Sydney University. Higher Degree Research Examination Handbook 2016. Available online: http://www.westernsydney.edu.au/_data/assets/pdf_file/0006/1064364/GRS_HDR_Examination_ Handbook_2016.pdf (accessed on 16 June 2016).

2. Maingueneau, D. Monolingualism and creativity: Scientific discourse and linguistic diversity in human and social sciences. Mètode Sci. Stud. J.-Annu. Rev. 2015, 6, 115-119. [CrossRef]

3. Holmen, A. Linguistic Diversity among students in higher education: A resource in a multilingual language strategy? In Transcultural Interaction and Linguistic Diversity in Higher Education; Fabricius, A., Preisler, B., Eds.; Palgrave Macmillan: Basingstoke, UK, 2015; pp. 116-141.

4. Mahboob, A.; Szenes, E. Linguicism and racism in assessment practices in higher education. Linguist. Hum. Sci. 2010, 3, 325-354. [CrossRef]

5. Moore, E. Conceptualising multilingual higher education in policies, pedagogical designs and classroom practices. Lang. Cult. Curric. 2016, 29, 22-39. [CrossRef]

6. Ngcobo, S. The struggle to maintain identity in higher education among Zulu-speaking students. Int. J. Biling. Educ. Biling. 2014, 17, 695-713. [CrossRef]

7. Van der Walt, C. Multilingual Higher Education: Beyond English Medium Orientations; Multilingual Matters: Bristol, UK, 2013.

8. Australian Education International (AEI). International Students Studying Science, Technology, Engineering and Mathematics (STEM) in Australian Higher Education Institutions. Available online: https:/ /internationaleducation.gov.au/research/ResearchSnapshots/Documents/STEM\%202014.pdf (accessed on 20 May 2016).

9. Mitchell, K. English is not all that matters in the education of secondary multilingual learners and their teachers. Int. J. Multicult. Educ. 2012, 14,1-21. [CrossRef]

10. Grosfoguel, R. The dilemmas of ethnic studies in the United States: Between liberal multiculturalism, identity politics, disciplinary colonization, and decolonial epistemologies. Hum. Archit. 2012, 10, 81-89. 
11. Gordin, M. Scientific Babel: The Language of Science from the Fall of Latin to the Rise of English; Profile Books: London, UK, 2015.

12. Singh, M.; Manathunga, C.; Bunda, T.; Qi, J. Mobilising Indigenous and non-Western theoretic-linguistic knowledge in doctoral education. Knowl. Cult. 2016, 4, 56-70.

13. Franceschini, R. Multilingualism and multicompetence: A conceptual view. Mod. Lang. J. 2011, 95, 344-355. [CrossRef]

14. Yildiz, Y. Beyond the Mother Tongue: The Postmonolingual Condition; Fordham University Press: New York, NY, USA, 2012.

15. Aronin, L.; Singleton, D. Multilingualism; John Benjamins: Amsterdam, The Netherlands, 2012.

16. Koven, M. Selves in Two Languages: Bilinguals' Verbal Enactments of Identity in French and Portuguese; John Benjamins: Amsterdam, The Netherlands, 2007.

17. Cruz-Ferreira, M. Multilingualism, language norms and multilingual contexts. In Multilingual Norms; Cruz-Ferreira, M., Ed.; Peter Lang: Frankfurt, Germany, 2010; pp. 1-18.

18. Harris, R. Integrationism. 2005. Available online: http://www.royharrisonline.com/integrationism.html (accessed on 5 April 2016).

19. García, O.; Wei, L. Translanguaging: Language, Bilingualism and Education; Palgrave Macmillan: London, UK, 2014.

20. Menken, K.; Shohamy, E. Invited colloquium on negotiating the complexities of multilingual assessment, AAAL Conference 2014. Lang. Teach. 2015, 48, 421-425. [CrossRef]

21. García, O.; Leiva, C. Theorizing and enacting translanguaging for social justice. In Heteroglossia as Practice and Pedagogy; Blackledge, A., Creese, A., Eds.; Springer: Dordrecht, The Netherland, 2014; pp. 199-216.

22. Cenoz, J. Defining multilingualism. Annu. Rev. Appl. Linguist. 2013, 33, 3-18. [CrossRef]

23. Kemp, C. Strategic processing in grammar learning: Do multilinguals use more strategies? Int. J. Multiling. 2007, 4, 241-261. [CrossRef]

24. Haugen, E. Bilingualism in the Americas: A Bibliography and Research Guide; University of Alabama Press: Tuscaloosa, AL, USA, 1956.

25. Beardsmore, H. Bilingualism: Basic Principles; Multilingual Matters: Clevedon, UK, 1986.

26. Wei, L. Dimensions of bilingualism. In The Bilingualism Reader; Wei, L., Ed.; Routledge: London, UK, 2000; pp. 3-25.

27. Jeoffrion, C.; Marcouyeux, A.; Starkey-Perret, R.; Narcy-Combes, M.F.; Birkan, I. From multilingualism to plurilingualism: University students' beliefs about language learning in a monolingual context. Lang. Cult. Curric. 2014, 27, 8-26. [CrossRef]

28. Moore, D.; Gajo, L. Introduction-French voices on plurilingualism and pluriculturalism: Theory, significance and perspectives. Int. J. Multiling. 2009, 6, 137-153. [CrossRef]

29. Council of Europe. Common European Framework of Reference for Languages: Learning, Teaching, Assessment; Language Policy Division: Strasbourg, France, 2001. Available online: http://www.coe.int/t/dg4/ linguistic/Source/Framework_EN.pdf (accessed on 12 June 2016).

30. Edwards, J. Bilingualism and multilingualism: Some central concepts. In The Handbook of Bilingualism and Multilingualism, 2nd ed.; Bhatia, T., Ritchie, W., Eds.; John Wiley: Oxford, UK, 2013; pp. 5-25.

31. Bloomfield, L. Language; Holt: New York, NY, USA, 1933.

32. Hall, R. Bilingualism and applied linguistics. Sprachtypol. Universalienforschung 1952, 6, 13-30. [CrossRef]

33. Edwards, J. Multilingualism; Routledge: London, UK, 1994.

34. Franceschini, R. The genesis and development of research in multilingualism. In The Exploration of Multilingualism: Development of Research on L3, Multilingualism and Multiple Language Acquisition; Larrisa, A., Britta, H., Eds.; John Benjamins: Amsterdam, The Netherlands, 2009; pp. 27-61.

35. Baker, C. Perceptions of bilinguals. Eur. J. Intercult. Stud. 1996, 7, 45-50. [CrossRef]

36. Hall, K.; Cheng, A.; Carlson, T. Reconceptualizing multicompetence as a theory of language knowledge. Appl. Linguist. 2006, 27, 220-240.

37. Hornberger, N. Opening and filling up implementational and ideological spaces in heritage language education. Mod. Lang. J. 2005, 89, 605-609.

38. Schalley, A.; Guillemin, D.; Eisenchlas, S. Multilingualism and assimilationism in Australia's literacy-related educational policies. Int. J. Multiling. 2015, 12, 162-177. [CrossRef] 
39. Liang, S. Language Attitudes and Identities in Multilingual China: A Linguistic Ethnography; Springer: Heidelberg, Germany, 2014.

40. Cenoz, J.; Gorter, D. Multilingual Education; Cambridge University Press: Cambridge, UK, 2015.

41. Wei, L. Moment analysis and translanguaging space: Discursive construction of identities by multilingual Chinese youth in Britain. J. Pragmat. 2011, 43, 1222-1235. [CrossRef]

42. Liddicoat, A. Multilingualism research in Anglophone contexts as a discursive construction of multilingual practice. J. Multicult. Discourses 2016, 11, 9-24. [CrossRef]

43. Chomsky, N. Cartesian Linguistics: A Chapter in the History of Rationalist Thought; Cambridge University Press: Cambridge, UK, 2009.

44. Sen, A. Development as capability expansion. In The Community Development Reader, 2nd ed.; DeFilippis, J., Saeger, S., Eds.; Routledge: New York, NY, USA, 2012; pp. 319-327.

45. Cook, V. The poverty of the stimulus argument and multi-competence. Second Lang. Res. 1991, 7, $103-117$. [CrossRef]

46. Canagarajah, S. Code-meshing in academic writing: Identifying teachable strategies of translanguaging. Mod. Lang. J. 2011, 95, 401-417. [CrossRef]

47. Michael-Luna, S.; Canagarajah, A. Multilingual academic literacies: Pedagogical foundations for code meshing in primary and higher education. J. Appl. Linguist. 2007, 4, 55-77. [CrossRef]

48. Jullien, F. On the Universal: The Uniform, the Common and Dialogue between Cultures; Polity Press: Cambridge, UK, 2014.

49. Hymes, D. On communicative competence. In Sociolinguistics; Pride, J., Holmes, J., Eds.; Penguin: London, UK, 1972; pp. 269-293.

50. Ruíz, R. Orientations in language planning. NABE J. 1984, 8, 15-34.

51. Cummins, J. Fundamental psycholinguistic and sociological principles underlying educational success for linguistic minority students. In Social Justice through Multilingual Education; Skutnabb-Kangas, T., Phillipson, R., Mohanty, A., Panda, M., Eds.; Multilingual Matters: Clevedon, UK, 2009; pp. 19-35.

52. García, O. Bilingual Education in the 21st Century: A Global Perspective; Wiley: Chichester, UK, 2009.

53. Hélot, C. Linguistic diversity and education. In The Routledge Handbook of Multilingualism; Martin-Jones, M., Blackledge, A., Creese, A., Eds.; Routledge: New York, NY, USA, 2012; pp. 214-231.

54. Turner, M.; Cross, R. Making space for multilingualism in Australian schooling. Lang. Educ. 2016, 30, $289-297$. [CrossRef]

55. Doiz, A.; Lasagabaster, D.; Sierra, J. What does 'international university' mean at a European bilingual university? The role of languages and culture. Lang. Aware. 2014, 23, 172-186. [CrossRef]

56. French, M. Students' multilingual resources and policy in-action: An Australian case study. Lang. Educ. 2016, 30, 298-316. [CrossRef]

57. Heller, M.; Pavlenko, A. Bilingualism and multilingualism. In Society and Language Use; Jaspers, J., Östman, J., Verschueren, J., Eds.; John Benjamins: Amsterdam, The Netherlands, 2010; pp. 71-83.

58. Shohamy, E. Assessing multilingual competencies: Adopting construct valid assessment policies. Mod. Lang. J. 2011, 95, 418-429. [CrossRef]

59. Choy, S.; Li, M.; Singh, P. The Australian doctorate curriculum: Responding to the needs of Asian candidates. Int. J. Res. Dev. 2015, 6, 165-182. [CrossRef]

60. Heugh, K. Epistemologies in multilingual education: Translanguaging and genre-companions in conversation with policy and practice. Lang. Educ. 2015, 29, 280-285. [CrossRef]

61. Baptista, A.; Frick, L.; Holley, K.; Remmik, M.; Tesch, J.; Åkerlind, G. The doctorate as an original contribution to knowledge: Considering relationships between originality, creativity, and innovation. Front. Learn. Res. 2015, 3, 55-67.

62. Poole, B. The rather elusive concept of 'doctorateness': A reaction to Wellington. Stud. High. Educ. 2015, 40, 1507-1522. [CrossRef]

63. Wellington, J. Searching for 'doctorateness'. Stud. High. Educ. 2013, 38, 1490-1503. [CrossRef]

64. Åkerlind, G.; McAlpine, L. Supervising doctoral students: Variation in purpose and pedagogy. Stud. High. Educ. 2015. [CrossRef]

65. Singh, M.; Ballantyne, C. Making Chinese learnable for beginning second language learners? In Dynamic Ecologies; Murray, N., Scarino, A., Eds.; Springer: Dordrecht, The Netherlands, 2014; pp. 199-214. 
66. Manathunga, C. Culture as a place of thought. In Of Other Thoughts: Non-traditional Ways to the Doctorate; Engels-Schwarzpaul, A., Peters, M., Eds.; Sense Publishers: Rotterdam, The Netherlands, 2013; pp. 67-82.

67. Qi, J. A networked-hutong siwei of critiques for critical teacher education. Asia-Pac. J. Teach. Educ. 2014, 42, 379-391. [CrossRef]

68. Singh, M. Using Chinese knowledge in internationalising research education: Jacques Rancière, an ignorant supervisor and doctoral students from China. Glob. Soc. Educ. 2009, 7, 185-201. [CrossRef]

69. Singh, M. Learning from China to internationalise Australian research education. Innov. Educ. Teach. Int. 2011, 48, 395-405. [CrossRef]

70. Singh, M.; Meng, H. Democratising western research using non-western theories: Rancière and mute Chinese theoretical tools. Stud. High. Educ. 2011, 38, 907-920. [CrossRef]

71. Hornberger, N.; Link, H. Translanguaging and transnational literacies in multilingual classrooms: A biliteracy lens. Int. J. Biling. Educ. Biling. 2012, 15, 261-278. [CrossRef]

72. Arya, D.J.; McClung, N.A.; Katznelson, N.; Scott, L. Language ideologies and literacy achievement: Six multilingual countries and two international assessments. Int. J. Multiling. 2016, 13, 40-60. [CrossRef]

73. Li, W.; Zhu, H. Translanguaging identities and ideologies: Creating transnational space through flexible multilingual practices amongst Chinese university students in the UK. Appl. Ling. 2013, 34, 516-535. [CrossRef]

74. Pennycook, A. Language as a Local Practice; Routledge: London, UK, 2010.

75. Lo Bianco, J. The importance of language policies and multilingualism for cultural diversity. Int. Soc. Sci. J. 2010, 61, 37-67. [CrossRef]

76. Gogolin, I. The 'monolingual habitus' as the common feature in teaching in the language of the majority in different countries. Per Ling. 2013, 13, 38-49. [CrossRef]

77. Hornberger, N. Multilingual education policy and practice: Ten certainties (grounded in Indigenous experience). Lang. Teach. 2009, 42, 197-211. [CrossRef]

(C) 2016 by the author; licensee MDPI, Basel, Switzerland. This article is an open access article distributed under the terms and conditions of the Creative Commons Attribution (CC-BY) license (http://creativecommons.org/licenses/by/4.0/). 